\title{
Effect of Supplementation of Antioxidant (Vitamin E), Trace Minerals (Selenium, Copper, Zinc) and Increased Energy Allowance on (certain) Serum Metabolites and Competence of Transition Crossbred Cows
}

\author{
A. Bhimte ${ }^{\text {* }}$, Y. Konyak ${ }^{2}$, B. Balamurugan ${ }^{3}$, L. Kipjen Singh ${ }^{3}$, \\ M. Sarkar ${ }^{2}$, G. Singh ${ }^{2}$ and V.P. Maurya ${ }^{2}$ \\ ${ }^{1}$ Animal Physiology Division, National Dairy Research Institute, \\ Karnal-132001, Haryana, India \\ ${ }^{2}$ Division of Physiology and climatology, ${ }^{4}$ Division of Animal Reproduction, \\ ICAR-Indian Veterinary Research Institute, Izzatnagar-243122, U.P., India \\ ${ }^{3}$ Animal Reproduction, Gynaecology and Obstetrics, National Dairy Research Institute, \\ Karnal-132001, Haryana, India \\ *Corresponding author
}

Keywords

Transition cows, Negative energy balance (NEB), Lipid mobilization, Body condition score (BCS), Non steroid fatty acids (NEFA), fatty liver, Dry matter intake(DMI)

Article Info

Accepted: 06 June 2018 Available Online: 10 July 2018

\section{A B S T R A C T}

The experiment was conducted to investigate the effect of antioxidant [vitamin E (vit E)] and trace minerals [selenium (Se), copper $(\mathrm{Cu})$, zinc $(\mathrm{Zn})$ ], high energy diet supplementation and its effect on allometric and physio-biochemical parameters in crossbred cows during transition period. For this, advanced pregnant crossbred cows $(\mathrm{n}=$ $20)$ of $2^{\text {nd }}$ to $4^{\text {th }}$ parity and lactation potential of $>10 \mathrm{~L} /$ day at 28 days prepartum were divided into two groups viz. control (CON) and treatment (TRT) consisting of 10 animals each. TRT group was supplemented with Vit E @ 80 IU/kg DMI + Se @ $0.3 \mathrm{mg} / \mathrm{kg}$ DMI+ $\mathrm{Cu} @ 15.7 \mathrm{mg} / \mathrm{kg}$ DMI + Zn @ $22 \mathrm{mg} / \mathrm{kg}$ DMI incorporated in wheat flour bolus from -4 to 8 week of calving and were provided with $20 \%$ additional concentrate from 2 to 8 week of calving to TRT group. CON group was given only basal diet without any supplementation. Physiological responses, body weight (B.wt) and body condition score (BCS) of each animal was recorded. Blood samples were collected on weekly interval from -4 to 8 week of calving. Glucose, triglyceride and total cholesterol were estimated from serum using commercial kits. BCS and B.wt were maintained significantly better $(\mathrm{p}<0.05)$ in TRT than CON group. Physiological responses showed better adaptation in TRT as compare to CON group. Plasma cholesterol, triglyceride $(\mathrm{p}<0.05)$ and glucose $(p<0.01)$ levels were also found significantly elevated in TRT versus CON group. Thus, Vit $\mathrm{E}, \mathrm{Se}, \mathrm{Cu}$ and $\mathrm{Zn}$ supplementation showed positive impact on overall health status and adaptability of the animals. 


\section{Introduction}

The transition period in dairy cows ( 3 week before and 3 week after parturition) represents a time of immense physiological stress for animals. The animal undergoes major physiological, nutritional, metabolic, endocrine and immunological changes to shift from non lactating to lactating state (Sordillo et al., 2013). A further challenge is that DMI during the transition period is generally insufficient to meet the energy requirements for lactation and maintenance (Drackley, 1999).

During transition period, the prepartum fetal growth and postpartum milk production increases the total energy demand on the animal. With the onset of lactation, additional metabolic activity of mammary gland increases by fourfold and approximately $85 \%$ of total body glucose is partitioned to mammary gland to sustain copious milk secretion. This increase in glucose demand during transition period is especially challenging, because little glucose is absorbed from the gastrointestinal tract in ruminants and lowered DMI also decreases propionate levels from rumen. This often leads to NEB (Janovick and Drackley, 2010; Schulz et al., 2014) and animal tries to compensate by lipid mobilization from adipose tissues to ensure availability of substrates for maintenance and milk production which results in increased concentrations of NEFA in bloodstream in the prepartum transition period (Dyk and Emery, 1996).

Cholesterol is the major precursor for most of steroid hormones and is directly related to milk production (Guedon et al., 1999). A reduction in total blood cholesterol and triglycerides was observed around transition period (Turk et al., 2004) which may be attributed to increase in oxidative stress (González et al., 2011; Djoković et al., 2013) and increased utilization for steroid hormone biosynthesis around parturition. Cholesterol levels are positively correlated to DMI; lower concentrations in feed restricted animals might be expected because of lower DMI. A significantly higher level of cholesterol has favorable effect on the synthesis of reproductive hormones in animals supplemented with bypass fat (Wadhwa et al., 2012).

Monitoring B.wt at calving and during early lactation is a useful tool for management of dairy cows during transition period. A positive correlation was observed between plasma NEFA, decline in BCS and increased incidence of health problems in dairy cattle (Buckley et al., 2003). Monitoring B.wt at calving and during early lactation is a useful tool for management of dairy cow. Rectal temperature (RT), pulse rate(PR) and respiration rate $(\mathrm{RR})$ acts as indicator of animal health status, as rise in temperature is manifested when animal is infected with pathogens as the immune system begins to fight the infection (Miedema et al., 2011).

Oxidative stress in transition cows is another contributing factor to immunosuppression and increased disease susceptibility. Metabolic demands associated with late pregnancy, parturition and initiation of lactation would be expected to increase the production of reactive oxygen species (ROS) as reported by Sordillo (2005). Oxidative stress increases the lipid peroxidation and causes cellular damage to tissues, specially the immune cells.

Vit E, as an antioxidant has important role in immune responsiveness and health in dairy cows (Weiss and Spears, 2006). A number of trace minerals are also required for functioning of enzymes involved in the antioxidant defense system and may affect immune cells via mechanisms distinct from antioxidant properties. 


\section{Materials and Methods}

All the experiments, procedures and protocols on animals were conducted following the approval of the institute animal Ethics Committee. The experiment involved twenty apparently healthy advanced pregnant crossbred cattle (Haryana/ Holstein Friesian/ Brown Swiss/Jersey) maintained at cattle and buffalo farm of Livestock Production and Management Section, Indian Veterinary Research Institute, Izatnagar. The institute is located at an altitude of 564 feet above the mean sea level, at latitude of $28-\mathrm{N}$ and a longitude of 79- E. The experimental cows were in $2^{\text {nd }}$ to $4^{\text {th }}$ parity with milk yield more than $10 \mathrm{~L} /$ day in their last lactation.

The experimental crossbred cows were divided into two groups ( $\mathrm{n}=10$ cows/group), viz. TRT and CON. Each cow was given access to fodder and water ad-libitum. Animals of TRT group were supplemented with vitamin E (DL-a-tocopherol acetate, $\mathrm{CDH}$, India), Selenium (Sodium selenite, $\mathrm{CDH}$, India), Copper (Copper sulfate, $\mathrm{CDH}$, India) and Zinc (Zinc sulfate, $\mathrm{CDH}$, India) as per oral dose rate of $80 \mathrm{IU} / \mathrm{kg}$ DMI, $0.3 \mathrm{mg} / \mathrm{kg}$ DMI, $15.7 \mathrm{mg} / \mathrm{kg}$ DMI and $22 \mathrm{mg} / \mathrm{kg}$ DMI (NRC 2001) respectively, in addition to standard feeding practices starting from -28 days pre-partum up to 56 days of lactation. These animals were then given $20 \%$ extra energy allowance (concentrate mixture) from 2 weeks after calving up to 8 weeks after calving. Cows in the TRT group were given wheat flour bolus which was used as vehicle to deliver Vit E and trace minerals. However, $\mathrm{CON}$ group was given only the basal diet.

B.wt of each animal was recorded before feeding between 7:30 am to 8:30 am daily using electronic weighing machine. Body condition was scored adopting a 5-point scale method. BCS basically describes the degree of fatness of an animal. A numerical range of 1 to 5 identifies varying degrees of fat cover. Physiological responses viz. rectal temperature $\mathrm{RT}$, respiration rate $\mathrm{RR}$ and pulse rate PR were recorded in both TRT and CON in the morning, afternoon and evening. RT $\left({ }^{\circ} \mathrm{F}\right)$ was recorded with digital thermometer while the RR (breaths/min) was recorded by counting the flank movements per minute from a distance of 4-5 $\mathrm{m}$ without disturbing the animals. The PR (beats/min) was recorded by palpating the middle coccygeal artery. Concentrations of glucose, total cholesterol and triglyceride were estimated using commercial kits (Span Cogent diagnostic kits, India) with standard method using double beam UV-Visible Spectrophotometer (Electronics Corporation of India Ltd., India). All experimental data are shown as mean \pm SEM. The statistical significance of differences in mean was assessed using the software SPSS.60 by repeated measure two ways ANOVA mixed model. Differences were considered significant at $\mathrm{p}<0.05$.

\section{Results and Discussion}

The DMI decreased during prepartum period and was the lowest on the day of calving in both groups. DMI started to increase after parturition which could be due to the need of higher energy for production of milk. Changes of BCS and B.wt in each experimental group are reported in table 1 . At the beginning of experiment (day 28 prepartum), BCS and B.wt was similar in all the cows. The CON group showed significantly higher reduction $(\mathrm{p}<0.05)$ in BCS and B.wt during pre and postpartum period of study than the supplemented group. The decrease in prepartum DMI has classically been attributed to rapid growth of fetus taking up the abdominal space and displacing rumen volume. However, other hormonal, physiological and stress related factors also have important impact on this phenomena postpartum (Robinson, 1997). 
Increased fetal growth prepartum and milk production postpartum leads to NEB in animal with subsequent mobilization of body stores and fall in BCS. The impact of NEB appeared to be less evident than the fall in B.wt and BCS in TRT as compared to CON group, which could be explained by the additional energy allowance along with trace minerals, Vit E and increased DMI in TRT group (Hayirli et al., 2002). Park et al., (2010) demonstrated the importance of appropriate nutrition during this period to minimize loss of body condition. Maurya (2011) reported that Vit $\mathrm{E}$ and $\mathrm{Zn}$ supplementation during dry period and early lactation minimized the loss of body condition, which is in agreement to the findings in our experiment. During peripartum period, Vit $\mathrm{E}$ and mineral supplementation also improved the performance of buffaloes.

Physiological responses (RT, RR, and PR) are the important indicators of health status of animal, usually elevated due to immunosuppressive state around calving (Mbiedema et al., 2011) which activates immune system causing release of various cytokines producing inflammatory response. The physiological responses recorded on the day of calving were lower in TRT as compared to CON group (Table 2). This shows an improvement in health and immune status of TRT group due to positive biological actions of antioxidants and trace minerals on overall physiological processes of the animals.

Table.1 to 2 Effect of Vit $\mathrm{E}$ and trace minerals ( $\mathrm{Se}, \mathrm{Cu}$ and $\mathrm{Zn}$ ) supplementation with additional energy on the allometric parameters: (a) B.wt (b) BCS and physiological parameters recorded in the morning: (a) RT (b) RR (c) PR

Table (1)

\begin{tabular}{|l|l|l|l|}
\hline \multicolumn{5}{|c|}{ Body weight $^{*}$} \\
\hline Group & Prepartum & Day of calving & Postpartum \\
\hline TRT & $468.75 \pm 13.76$ & $414.25 \pm 3.78^{\mathrm{a}}$ & $416.69 \pm 10.49^{\mathrm{a}}$ \\
\hline CON & $462.25 \pm 13.12$ & $398.48 \pm 4.39^{\mathrm{b}}$ & $383.32 \pm 9.84^{\mathrm{b}}$ \\
\hline \multicolumn{4}{|c|}{ Body condition score $^{*}$} \\
\hline TRT & $3.75 \pm 0.06$ & $3.36 \pm 0.13^{\mathrm{a}}$ & $2.90 \pm 0.16^{\mathrm{a}}$ \\
\hline CON & $3.50 \pm 0.04$ & $3.02 \pm 0.10^{\mathrm{b}}$ & $3.50 \pm 1.11^{\mathrm{b}}$ \\
\hline
\end{tabular}

Table (2)

\begin{tabular}{|l|l|l|l|}
\hline Group & Prepartum & \multicolumn{1}{l|}{ At calving } & \multicolumn{1}{l|}{ Postpartum } \\
\hline \multicolumn{5}{|c|}{ TRT } & $99.33 \pm 0.15$ & $101.1 \pm 0.61$ & $99.35 \pm 0.36$ \\
\hline CON & $100.33 \pm 0.26$ & $103.15 \pm 0.18$ & $100.26 \pm 0.31$ \\
\hline & & Pulse rate & \\
\hline TRT & $40.91 \pm 1.19$ & $51.83 \pm 2.17$ & $39.11 \pm 0.63$ \\
\hline CON & $41.83 \pm 3.17$ & $63.17 \pm 1.85$ & $41.31 \pm 2.44$ \\
\hline & & Respiration rate \\
\hline TRT & $33.08 \pm 6.14$ & $49.67 \pm 2.29$ & $34.17 \pm 1.10$ \\
\hline CON & $37.20 \pm 8.11$ & $59.17 \pm 1.90$ & $36.79 \pm 2.59$ \\
\hline
\end{tabular}

*Means within rows with different superscript are significantly differ $(\mathrm{p}<0.05)$ 
Fig.1 Effect of Vit E and Se supplementation with additional energy on the serum concentration of (A) glucose (B) triglyceride (C) cholesterol during the transition period in crossbred cow (Mean \pm SE)

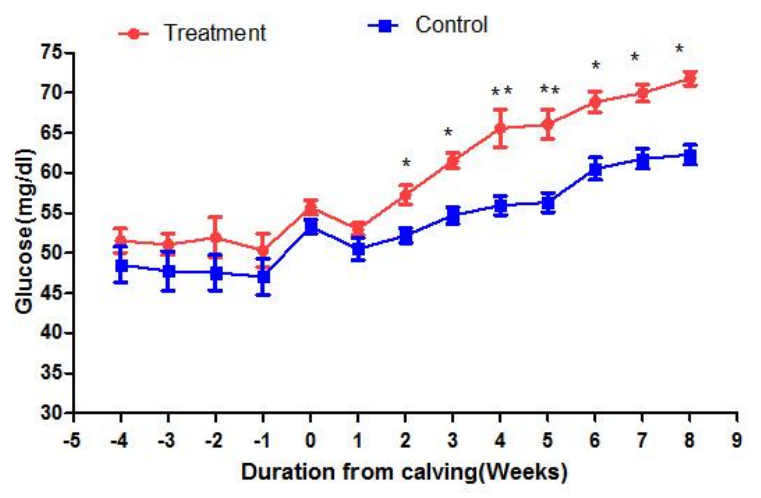

(A)

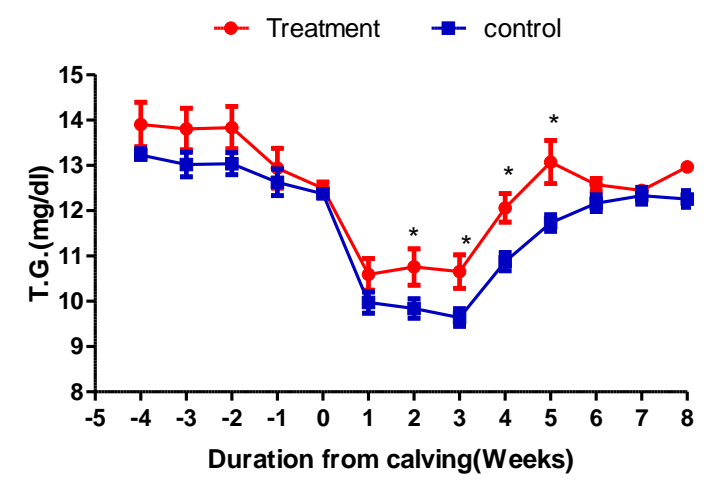

(B)

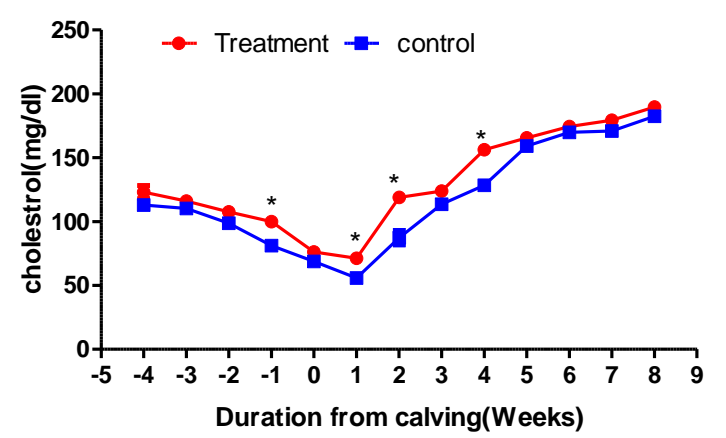

(C)

*Single and $* *$ double asterisk represent significance at $5 \%$ and $1 \%$, respectively. 
A decline in plasma concentration of glucose was observed starting from $30^{\text {th }}$ day before calving and reaches minimum levels on day 3 postpartum (Bell and Bauman, 1997). In our study, plasma glucose levels recorded pre and postpartum in blood samples collected at weekly intervals was higher (Fig.1A) in TRT as compared to CON group and was significantly higher $(\mathrm{p}<0.01)$ on the day of calving, $3^{\text {rd }}$ and $6^{\text {th }}$ week of experiment as compare to other days. Glucose is the primary energy substrate for animal, having important role in milk production and fetal growth. Changes in glucose concentrations during post parturient period is due to decreased DMI, increased nutrient demand for milk production and changes in hormones such as cortisol that promote gluconeogenesis and glycogenolysis (Drackley et al., 2001). Lactose is a major component in milk; gluconeogenesis is closely linked to lactogenesis as the amount of available glucose determines the quantity of milk produced. During NEB in early lactation, the rapid increase in utilization of glucose for milk lactose production results in lower plasma concentration of both glucose and insulin as compared to later stages of lactation (Doepel et al., 2002). Around parturition, glucose concentration decreased and NEFA concentration increased due to lipolysis, which acts as an alternative energy source (Shehab-El-Deen et al., 2010). CON group produced more NEFA and had lower blood glucose level as compared to TRT group which is due to reduction in DMI and increase in lipolysis to optimize the glucose demand. The decrease in blood glucose concentration recorded in this study post calving may be attributed to several hormonal changes occurring mainly to adjust the parturition and lactation requirements and partially, to regulate body metabolism leading to postpartum hypoglycemic state (Komatsu et al., 2005).
In the present experiment, cholesterol (Fig.1C) was significantly $(\mathrm{p}<0.05)$ higher -1 week prepatum and +2 week onwards, however the triglyceride (Fig.1B) was significantly $(\mathrm{p}<0.05)$ higher at +1 week onwards in TRT group. There was decreased cholesterol and triglyceride levels at calving and postpartum in both the experimental groups; more pronounced in $\mathrm{CON}$ group because of elevated NEFA. The increased demand of steroid hormones during gestation to sustain pregnancy (progesterone) and preparation of mammary glands for subsequent lactation (estrogen, progesterone), can be considered the primary causes to decrease the total serum cholesterol concentrations in the last phase of pregnancy in dairy cattle (Pysera and Opalka, 2000). The response could be associated with NEB during this period (Herdt, 2000). The fat content of cow's milk diverge from less than $3 \%$ to more than $6 \%$, depending on the breed and phase of lactation. Milk fat is principally composed of triglycerides (97-98\%), therefore the uptake by mammary gland for milk fat production during the course of lactation can be a contributing factor for reduction in triglyceride concentration post calving (Džidić, 1999). Contradictory result showed an increase in triglyceride levels during NEB at calving (Khan et al., 2015). However, similar results have been reported by various researchers demonstrating an increase in concentrations of total lipid and triglycerides at parturition (Douglas et al., 2004).

In conclusion, this experiment strengthens the consideration that the periparturient period is the most stressful period for dairy cows, owing to a lot of exogenous and endogenous changes occurring in the animals affecting the immune system, blood metabolites and health status. Thus it can be concluded that Implementation of nutritional strategies aimed at improving metabolic function, delivering bioactive nutrients and supporting antioxidant 
systems helps to prevent a vicious cycle that can sustain both subclinical infections and metabolic dysfunction.

\section{Acknowledgements}

The authors would like to thank the Director, ICAR-IVRI and also extend gratitude to PI (project code IVRI/P\&C/15-18/006) for providing the facilities for the execution of this experiment. We are grateful to the technical staff at NRL, IVRI and farm employees at LPM section, IVRI for their diligent support.

\section{References}

Bell, A.W. and Bauman, D.E. 1997. Adaptations of glucose metabolism during pregnancy and lactation. Journal of Mammary Gland Biology and Neoplasia. 2: 265-278.

Buckley, F., O’Sullivan, K., Mee, J.F., Evans, R.D., Dillon, P. 2003. Relationships among milk yield, body condition, cow weight and reproduction in spring-calved HolsteinFriesians. Journal of Dairy Science. 86:2308-2319.

Džidić, A. 1999. Physiology of Lactation and Machine Milking. Mljekarstvo. 49: 163-174.

Djokovic, R.D.A., Kurcubic, V.K.L., Ilic, ZIO., Cincovic, M.C.A., Petrovic, M.P.I., Fratric, N.F.A. and Jasovic, B.J.O. 2013. Evaluation of metabolic status in Simmental dairy cows during late valuation of metabolic status in Simmental dairy cows during late pregnancy and early lactation. Veterinarski Arhiv. 83 (6): 593-02.

Doepel, L., Lapierre, H. and Kennelly, J.J. 2002. Peripartum performance and metabolism of dairy cows in response to prepartum energy and protein intake. Journal of Dairy Science.
85:2315-2334.

Douglas, G.N., Overton, T.R., Bateman, H.G., Drackley, J.K. 2004. Peripartal metabolism and production of Holstein cows fed diets supplemented with fat during the dry period. Journal of Dairy Science. 87: P. 4210-4220.

Drackley, J.K. 1999. Biology of dairy cows during the transition period: The final frontier? Journal of Dairy Science. 82: 2259-2273

Drackley, J.K., Overton, T.R., Douglas, G.N. 2001. Adaptations of glucose and long-chain fatty acid metabolism in liver of dairy cows during the periparturient period. Journal of Dairy Science. 84:100-112.

Dyk, P. and Emery, R. 1996. Reducing the incidence of peripartum health problems. Proc. Tri-State Dairy Nutr. Conf., M.L. Eastridge, ed.

Gonzales, F.D., Muino, R., Pereira, V. and Campos, R. 2011. Relationship among blood indicators of lipo mobilization and hepatic function during early lactation in high-yielding dairy cows. Journal of Veterinary Science. 12 (3): 251-55.

Guédon, L., Saumande, J., Dupron, F., Couquet, C. and Desbals, B. 1999. Serum cholesterol and triglycerides in postpartum beef cows and their relationship to the resumption of ovulation. Theriogenology. 51:14051415.

Hayirli, A., Grummer, R.R., Nordheim, E.V., Crump, P.M. 2002. Animal and dietary factors affecting feed intake during the pre-fresh transition period in Holsteins. Journal of Dairy Science. 85:3430-3443.

Herdt. 2000. Ruminant adaptation to negative energy balance. Influences on the etiology of ketosis and fatty liver. Veterinary Clinics of North AmericaFood Animal Practice. 16:215-30. 
ICAR. 2013: Nutrient requirement of cattle and buffalo ICAR New Delhi third edition $\mathrm{pp} 32$.

Janovick, N.A., Drackley, J.K. 2010. Prepartum dietary management of energy intake affects postpartum intake and lactation performance by primiparous and multiparous Holstein cows. Journal of Dairy Science. 93:3086-3102.

Khan, H.M., Mohanty, T.K., Bhakat, M., Gupta, A.K., Tyagi, A.K. and Mondal, G. 2015. Effect of vitamin E and mineral supplementation on biochemical profile and reproductive performance of buffaloes. Buffalo Bulletin. 34: 63-72.

Komatsu, Y., Itoh, F., Kushibiki, S. and Hodate, K. 2005. Changes in gene expression of glucose transporters in lactating and nonlactating cows. Journal of Animal Science. 83: 557564.

Maurya, P. 2011. NDRI (deemed University); Karnal, India. Leptin level in relation to immunity, energy metabolites and cellular adaptations during dry period and early lactation in crossbred cows. M.V.Sc. Thesis.

Miedema, H.M., Cockram, M.S., Dwyer, C.M. and Macrae, A.I. 2011. Behavioral predictors of the start of normal and dystocic calving in dairy cows and heifers. Applied Animal Behaviour Science. 132:14-19.

NRC (National Research Council). 2001. Nutrients Requirements of Dairy Cattle. 7th revised edition, National Academy Press, Washington.

Park, A.F., Shirley, J.E., Titgemeyer, E.C., Cochran, R.C., DeFrain, J.M., Wickersham, E.E. and Johnson, D.E. 2010. Characterization of plasma metabolites in Holstein dairy cows during the periparturient period. International Journal of Dairy
Science. 5:253-263.

Pysera, B. and Opalka, A. 2000. The effect of gestation of dairy cows on lipid and lipoprotein patterns and composition in serum during winter and summer feeding. Journal of Animal Feed Science and Technology. 9: 411-24.

Robinson, P.H. 1997. Effect of yeast culture (Sacchromyces cerevisiae) on adaptation of cows to diets postpartum. J. Dairy Sci. 80:11191125.

Saeed, A., Khan, I.A. and Hussein, M.M. 2009. Change in biochemical profile of pregnant camels (Camelus dromedaries) at term. Comparative Clinical Pathology. 18: 139- 143.

Schulz, K., Frahm, J., Meyer, U., Kersten, S., Reiche, D., Rehage, J. and Dänicke, S. 2014. Effects of prepartal body condition score and peripartal energy supply of dairy cows on postpartal lipolysis, energy balance and ketogenesis: An animal model to investigate subclinical ketosis. Journal of Dairy Research. 81: 257-266.

Shehab-El-Deen, M.A., Fadel, M.S., Soom, A.V., Sherif, Y.S., Maes, D., Leroy, M.R. and Jo, L. 2010. Circadian rhythm of metabolic changes associated with summer heat stress in high-producing dairy cattle. Tropical Animal Health Production. 42:11191125.

Sordillo, L.M. 2005. Factors affecting mammary gland immunity and mastitis susceptibility. Livestock Production Science 98, 89-99.

Sordillo, L.M. and Raphael, W. 2013. Significance of metabolic stress, lipid mobilization, and inflammation on transition cow disorders. Veterinary Clinics of North America-Food Animal Practice. 29: 267-278.

Spears JW and Weiss WP. 2008. Role of antioxidants and trace elements in 
health and immunity of transition dairy cows. Veterinary Journal. 176:70-76.

Turk. R., Juretic, D., Geres, D., Turk, N., Rekic, B., Simeon-Rudolf, V. and Svetina, A. 2004. Serum paraoxonase activity and lipid parameters in the early postpartum period of dairy cows. Veterinary Science Research Journal. 76: 57-61.

Wadhwa, M., Grewal, R.S., Bakshi, M.P.S. and Brar, P.S. 2012. Effect of supplementing bypass fat on the performance of high yielding crossbred cows. Indian Journal of Animal Science. 82: 200-203.

Weiss, W.P. and Spears, J.W. 2006. Vitamin and trace mineral effects on immune function of ruminants. In: Sejrsen, K., Hvelplund, T., Nielsen, M.O. (Eds.), Ruminant Physiology. Wageningen Academic Publishers, Utrecht, the Netherlands, pp. 473-496.

\section{How to cite this article:}

Bhimte, A., Y. Konyak, B. Balamurugan, L. Kipjen Singh, M. Sarkar, G. Singh and Maurya, V.P. 2018. Effect of Supplementation of Antioxidant (Vitamin E), Trace Minerals (Selenium, Copper, Zinc) and Increased Energy Allowance on (certain) Serum Metabolites and Competence of Transition Crossbred Cows. Int.J.Curr.Microbiol.App.Sci. 7(07): 439-447. doi: https://doi.org/10.20546/ijcmas.2018.707.053 